\title{
Circumcision of children with hemophilia in local places
}

\author{
Goksel Leblebisatan* \\ Medical Faculty, Internal Medical Sciences, Department of Pediatrics, Cukurova University, Turkey
}

Circumcision in some countries, is one of the most common surgical interventions in patients of hemophilia, although it is a controversial issue among medical professionals [1]. Here, retrospective evaluation for 18 circumcised hemophilia patients from the 92 ones followed up in Local Children Hospital at 2 year follow up period presented. They are classified as severe (4), moderate (10), mild (1) Haemophilia A and severe (1) and moderate (2) Haemophilia B. All patients were screened for factor inhibitor 1-30 days before. Patients received oral tranexamic acid $(15 \mathrm{mg} \mathrm{kg})$ three times a day for 1 week, first dose was given $24 \mathrm{~h}$ before circumcision.

The surgeries were planned to elevate deficient factor to $100 \%$ of control and after $50 \%$ for 3 days. Factor concentrates were applied in 8 hour intervals for first and 12 hours for next days. In the circumcisions, surgical saturation with effective cauterization done by the surgeons. If the patient revealed bleeding, extra bolus injections of factor concentrates were administered. All of the caregivers gave written informed consent before the procedure. Only one patient developed bleeding complication after discharge of $3^{\text {rd }}$ day and was treated with factor replacement for a week. None of the patients developed factor inhibitor after a minimal 6 maximum 18 months intervals as they are screened for it. The ages of patients ranged between 1 and 14 years with mean value $6.7 \pm 4.4$ years.

In Muslim communities, people must be circumcised according to their religious beliefs. As medical consequences are concerned, circumcision brings some discussions in other countries. Although the American Academy of Pediatrics (AAP) decide that the benefits of circumcision are not significant enough to recommend circumcision as a routine procedure [2] it is the most common procedure in the Plastic surgery clinics in that country [3]. As we compare literature datas [4,5] the rate of the circumcision almost 9-10 patient circumcision per year for 2 year reveals that there were hemophiliac children that couldn't be circumcised although family's great desire because of incapability of the surgery before.

In our population, circumcision may be assumed essential if child and family desire the circumcision. As more hematology and surgery departments with laboratory facilities get together, procedure may be performed more commonly and safely. So, that unnecessary social and psychological pressures and some other medical problems may be resolved.

\section{References}

1. Rodriguez V, Titapiwatanakun R, Moir C, Schmidt KA, Pruthi RK (2010) To circumcise or not to circumcise? Circumcision in patients with bleeding disorders. Haemophilia 16: $272-276$.

2. [No authors listed] (1999) Circumcision policy statement. American Academy of Pediatrics. Task Force on Circumcision. Pediatrics 103: 686-693. [Crossref]

3. Niku SD, Stock JA, Kaplan GW (1995) Neonatal circumcision. Urol Clin North Am 22: 57-65. [Crossref]

4. Morris BJ (2007) Why circumcision is a biomedical imperative for the 21(st) century. Bioessays 29: 1147-1158. [Crossref]

5. Karaman MI, Zulfikar B, Caskurlu T, Ergenekon E (2004) Circumcision in hemophilia a cost-effective method using a novel device. J Pediatr Surg 39: 1562-1564. [Crossref]
Copyright: (C)2017 Leblebisatan G. This is an open-access article distributed under the terms of the Creative Commons Attribution License, which permits unrestricted use, distribution, and reproduction in any medium, provided the original author and source are credited.
Correspondence to: Goksel Leblebisatan, Medical Faculty, Internal Medical Sciences, Department of Pediatrics, Cukurova University, Turkey, Tel: +90 322 3386060; E-mail: gokselleb@gmail.com

Received: March 11, 2017; Accepted: March 20, 2017; Published: March 22, 2017 